diagnosis: case studies. Neuropsychiatr Dis Treat. 2010;6:473-481.

3. Jones $R$, Yates WR, Williams S, Zhou M, Hardman L. Outcome for adjustment disorder with depressed mood: comparison with other mood disorders. J Affect Disord. 1999;55(1):55-61. doi:10.1016/s0165-0327(98)00202-x

4. Strain JJ, Diefenbacher A. The adjustment disorders: the conundrums of the diagnoses. Compr Psychiatry. 2008;49(2):121-130. doi:10,1016/j.comppsych.2007.10.002

5. Nguyển Hoàng Yến. Nghiên cứu đắc điểm lâm sàng rôi loạn sự thích ứng ở bệnh nhân điều trị nội trú tại Viện
Sức khởe Tâm thân. Published online 2015.

6. Nguyển Thị Phương Loan. Nghiên cứu đặc điểm lâm sàng của trâm cảm có loạn thần ở người cao tuổi. Published online 2013.

7. Gradus JL, Qin $\mathbf{P}$, Lincoln AK, Miller M, Lawler E, Lash TL. The association between adjustment disorder diagnosed at psychiatric treatment facilities and completed suicide. Clin Epidemiol. 2010;2:23-28.

8. Kovács I, Vargha A, Ali I, Bódizs R. [Dream quality, trauma and suicide in in adjustment disorder]. Psychiatr Hung Magy Pszichiatriai Tarsasag Tudomanyos Folyoirata. 2010;25(1):62-73.

\title{
HẸP PHÌ ĐẠI CƠ MÔN VI Ở TRẺ SƠ SINH NON THÁNG: BÁO CÁO CA BÊNH
}

\author{
Trần Anh Quỳnh*, Lê Quang Dư*, Bùi Văn Lâm*, \\ Lê Hoàng Long*, Nguyễn Thị Minh Huyền*
}

\section{TÓM TẮT}

Hẹp phì đại cơ môn vị là một bệnh xảy ra ở tuân thứ hai sau sinh, không rõ nguyển nhân, bao gồm hẹp môn vị do phì đại cơ đồng tâm, gây tă̆c nghẽn đường ra da dày kèm theo nôn nhiều dần dấn đến suy dinh dưỡng, mất nước, và rối loạn chuyển hóa nghiêm trọng. Hẹp phì đại cơ môn vị cực kỳ hiếm ở trẻ sơ sinh non tháng và hiểm khi được báo cáo trong y văn. Báo cáo này là của một trẻ sở sinh non tháng, cân nặng lúc sinh thấp bi hep phì đai cơ môn vị. Bênh nhân xuất hiện nôn ra sữa lúc 4 ngày tuổi, chướng bụng vùng thượng vị và có bóng da dày giãn trên phim $X$ quang bụng. Trẻ được điều trị theo hướng trào ngược dạ dày thực quản nhưng bệnh không có tiến triển, trẻ vẫn nôn dịch sữa. Chụp lưu thông dạ dày-ruột chỉ thấy dạ dày giãn to. Siêu âm lại ổ bung vào ngày thứ 10 thấy cơ môn vị dày. Bệnh nhân được phẫu thuật mở cơ môn vị bằng phẫu thuật mở. diễn biến sau mổ bệnh nhân tốt lên không nôn ra sữa. xuất viện sau 1 tuần.

\section{SUMMARY \\ HYPERTROPHIC PYLORIC STENOSIS IN A PRETERM NEWBORN: A CASE REPORT}

Hypertrophic pyloric stenosis is a disease that occurs in the second week of life, of unknown origin, which consists of the narrowing of the pylorus due to concentric muscular hypertrophy, causing gastric outlet obstruction with progressive vomiting that leads to malnutrition, dehydration, and serious metabolic disorders. Hypertrophic pyloric stenosis is exceedingly rare in newborns and is rarely reported in the literature. This report is of a premature newborn, low birth weight with hypertrophic pyloric stenosis. The

*Bênh viên Nhi Trung Uơng

Chịu trách nhiệm chính: Trần Anh Quỳnh

Email: tranquynh.nhp@gmail.com

Ngày nhận bài: 17.9.2021

Ngày phản biên khoa hoc: 15.11.2021

Ngày duyệt bài: 25.11.2021 patient presented with vomiting milk at 4 days of age epigastric distension and dilated gastric shadow on the abdominal radiograph. The child was treated in the direction of gastroesophageal reflux but the disease did not progress, the child still vomited milk fluid. Gastrointestinal circulation with contrast showed only dilated stomach. Re-ultrasound on day 10 showed thickened pylorus. The patient underwent pyloromyotomy with open surgery. Postoperative progress, the patient improved without vomiting milk, discharged after 1 week.

\section{I. ĐĂTT VẤN ĐỀ}

Hẹp môn vị phì đại là một bệnh có biểu hiện lâm sàng rõ ràng, có tỷ lệ mắc bệnh từ 1,5 đến 4,0 trên 1000 ca sinh sống ở trẻ sơ sinh da trắng. Hẹ môn vị phì đại ít phổ biến hơn ở trẻ em người Mỹ gốc Phi và người Châu Á [1].

Mặc dù vẩn còn tranh cãi về căn nguyên, nhưng độ tuổi biểu hiện điển hình là ở tuân thứ hai đến tuân thứ tư của cuộc đời. Hẹp phì đại cơ môn vị cực kỳ hiếm ở trẻ sơ sinh và hiếm khi được báo cáo trong y văn [2]. Trẻ sơ sinh bị hẹp môn vị thường có biểu hiện như nôn không thành từng đợt, có thể tiến triển đến mất nước, sụt cân tiến triển và nhiễm kiềm chuyển hóa giảm clo huyết và hạ kali huyết. Chính vì thế ở trẻ sơ sinh non tháng thường dễ nhâm lẫn chẩn đoán với các bệnh lý nội khoa như co thắt môn vị, trào ngược dạ dày - thực quản. Hẹp phì đại cơ môn vị được điều trị bằng phẫu thuật mở cơ môn vị với tiên lượng tốt [1]. Trong báo cáo này chúng tôi trình bày một ca bệnh ở trẻ sơ sinh non tháng cân nặng thấp được điêuu trị theo hướng trào ngược da dày thực quản, sau phát hiện bệnh lý hẹp phì đại cơ mổn vị và được phẫu thuật mổ mở cơ môn vị khi trẻ 10 ngày tuổi. 


\section{BÁO CÁO CA BÊNH}

Trẻ nam sơ sinh non tháng, mẹ lớn tuổi (35 tuổi), đã 2 lần sinh non, khi mang thai mẹ không sử dụng thuốc gì đặc biệt, đẻ mổ vào tuân thai thứ 32, cân năng khi sinh $1.3 \mathrm{~kg}$. Sau đẻ, phát hiện suy hô hấp, được điêu trị suy hô hấp trong 3 ngày, trẻ được sử dụng kháng sinh thế hệ 3 phổ rộng, truyền dịch nuôi dưỡng. Trẻ được cho ăn sữa mẹ vào ngày thứ 4 sau đẻ. Tuy nhiển, trẻ nôn liên tục dịch sữa và cặn sữa, chướng bụng vùng thượng vị, đã được đặt xông dạ dày và chụp X-Quañ bụng không chuẩn bị thấy bóng hơi dạ dày vẫn giãn to, siêu âm ổ bụng vào ngày thứ 6 với kết quả da dày giãn, khổng đánh giá được cơ môn vị. Trẻ được điêu trị theo hướng trào ngược dạ dày-thực quản nhưng bệnh không có tiến triển, trẻ vẫn nôn dịch sữa và cẳn sữa.

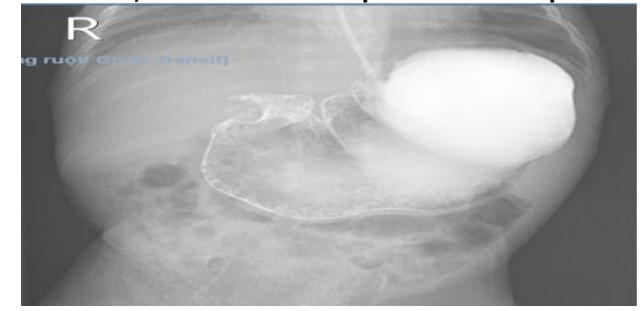

Hình 1: Da dày giãn to

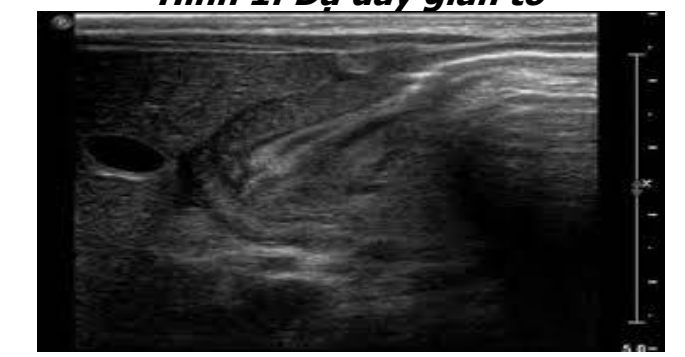

Hình 2: Hình ảnh siêu âm cơ môn vị dày

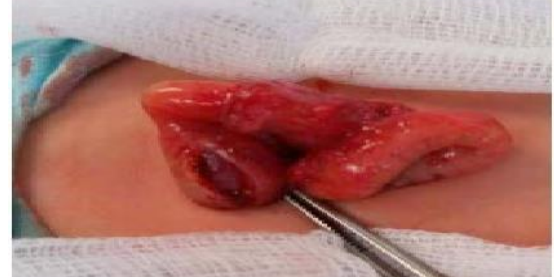

Hình 3: Mở cơ môn vị ngoài niêm mạc

Trẻ được chụp lưu thông dạ dày-ruột thấy dạ dày giãn to (hình 1). Siêu âm lại ổ bụng vào ngày thứ 10 , kích thước cơ môn vị dây $5 \mathrm{~mm}$ trên đoạn dài $8 \mathrm{~mm}$ (hình 2). Trẻ được chẩn đoán hẹp phì đại cơ môn vị. Trẻ được phẫu thuật mở cơ môn vị ngoài niêm mạc theo kỹ thuật Ramstedt theo đường trắng giữa trên rốn (hình 3 ), trong mổ đánh giá cơ môn vị hình quả lê, dây $5 \mathrm{~mm}$, dài $10 \mathrm{~mm}$. Sau mổ, trẻ được cho ăn vào ngày thứ 3 và ra viện sau 1 tuần. Khám lại sau 1 tháng, 3 tháng thấy trẻ ăn tốt, lên cân, không còn nôn.

\section{BÀN LUÂN}

Mặc dù hẹp phì đại cơ môn vị ở trẻ sơ sinh non cân non tháng là cực kỳ hiếm, nhưng cũng đã có những báo cáo đợ lẻ. Bệnh nhân nhỏ tuổi nhất được báo cáo là một thai nhi 7 tháng tuổi phát hiện hẹp phì đại cơ môn vị khi khám nghiệm tử thi. Như Zenn và Redo đã nêu, chỉ có $5 \%$ trong số các bệnh nhân hẹp phì đại cơ môn vị có các triệu chứng khi mới sinh [3]. Mặc dù có triệu chứng nhưng rất ít các trường hợp được tiến hành phẩu thuật trong những tuân đâu sau sinh. Điều này có thể liên quan đến sự hiếm hoi các triệu chứng lâm sàng và thiếu các tiêu chuẩn chẩn đoán. Do đó cần có các dấu hiệu và chỉ số trên siêu âm nghi ngờ để chẩn đoán hẹp phì đại cơ môn vị ở tuổi sơ sinh, đặc biệt là trẻ non cân non tháng.

Triệu chứng lâm sàng phổ biến ở trẻ mắc hẹp phì đại cơ môn vị thường có giai đoạn khoảng 3 tuần trở lên không có triệu chứng, gọi là khoảng trông, sau đó triệu chứng thường gặp nhất là nôn $(99.7 \%)$, chủ yếu là nôn ra cặn sữa, khám thây khối cơ môn vị (48\%), khônng tăng cân (46\%), mất nước (32\%), rối loạn điện giải gặp ở $67 \%$ bệnh nhân [2]. Chẩn đoán có thể dựa vào triệu chứng lâm sàng, nhưng hiện nay chủ yếu dựa vào hình ảnh cơ môn vị trên siêu âm với độ dày cơ môn vị $\geq 4 \mathrm{~mm}$ và chiều dài $\geq 16 \mathrm{~mm}$ [5]. Forster và cộng sự nghiên cứu trên 187 bênh nhân và khuyến cáo áp dụng tiêu chuẩn độ dày cơ môn vị $\geq 3 \mathrm{~mm}$ trên đoạn dài $\geq 17 \mathrm{~mm}$ cho mọi lứa tuổi. Marie và cộng sự nghiên cứu 287 bệnh nhân đưa ra khuyến cáo bộ ba chẩn đoán bao gồm: độ dày cơ môn vị $\geq 2.5 \mathrm{~mm}$, chiều dài $\geq 14 \mathrm{~mm}$ và có tắc nghẽn đường ra dạ dày [6].

Mặc dù các yêu tố sinh học trong quá trình phì đại cơ môn vị thường xẩy ra ở trẻ đủ tháng từ tuần thứ 3 trở đi, bệnh nhân của chúng tôi chứng tỏ rất hiếm khi gặp hẹp phì đại cơ môn vị ở lứa tuổi sơ sinh non cân. Việc điều trị nội khoa không cải thiện khiến chúng tổi cần tìm thềm các nguyên nhân bệnh lý ngoại khoa. Trong lần siêu âm đầu tiên chúng tôi không đánh giá được kích thước của cơ môn vị, lý do giải thích cho việc này là khi đó chúng tôi chưa nghĩ tới chẩn đoán hẹp phì đại cơ môn vị. Với lần thứ 2 siêu âm chúng tôi đã chú ý đánh giá cơ môn vị và thấy kích thước cơ môn vị dầy $5 \mathrm{~mm}$, dài $8 \mathrm{~mm}$. Cho đến nay không có báo cáo đầy đủ về chỉ số cơ môn vị đánh giá trên siêu âm cho trẻ sơ sinh non cân. Mặt khác mối lo ngại về kết quả âm tính giả 
trên siêu âm cũng được Keckler và các cộng sự lo ngại [7]. Việc thiết lập các tiêu chí chẩn đoán hẹp phì đại cơ môn vị ở trẻ sơ sinh non cân cần có số lượng bệnh nhân nhiều hơn. Trẻ sơ sinh non cân với các đặc điểm lâm sàng tắc nghẽn dạ dày, dạ dày giãn lặp lại trên các phim X-Quang cần nghi ngờ đến bệnh lý hiếm gặp này. Khi có các dấu hiệu ủng hộ trên siêu ẩm, việc phẫu thuật được đặt ra ngay thời điểm đó chứ không nên trì hoãn mặc dù các thông số cơ môn vị có thể thay đổi đối với trẻ non cân.

Phẫu thuật mở cơ môn vị vẫn là điều trị tiêu chuẩn cho hẹp phì đại cơ môn vị, tùy từng case bệnh cũng như tùy điều kiện từng nơi mà có thể làm nội soi hoặc mổ mở [4]. Trường hợp của chúng tôi bệnh nhân non tháng, nhẹ cân nên chúng tôi chọn phương án mổ mở, không gặp biến chứng trong và sau mổ.

\section{KẾT LUÂ̂N}

Hẹp phì đại cơ môn vị có thể gặp ở trẻ non tháng, nhẹ cân trong lứa tuổi sơ sinh ngay cả khi triệu chứng lâm sàng không điển hình như đã nêu trong y văn. Điều này có thể sẽ làm chậm quá trình chẩn đoán và điều trị khiến tăng thời gian nằm viện, dễ gặp biến chứng như mất nước, rối loạn điện giải, không tăng cân. Do đó việc xây dựng tiểu chẩn đoán riêng cho nhóm bệnh này bao gồm triệu chứng lâm sàng, siêu âm ổ bụng và chụp lưu thông ruột để có chiến lược điều trị cụ thể, tránh các biến chứng là cần thiết.

\section{TÀI LIÊU THAM KHẢO}

1. Mitchell L.E., Risch N. (1993) The genetics of infantile hypertrophic pyloric stenosis. A reanalysis. Am J Dis Child; 147:1203-11

2. Taylor N.D., Cass D.T., and Holland A.J.A. (2013). Infantile hypertrophic pyloric stenosis: has anything changed?. J Paediatr Child Health, 49(1), 33-37.

3. Zenn M.R. and Frank Redo S. (1993). Hypertrophic pyloric stenosis in the newborn. Journal of Pediatric Surgery, 28(12), 1577-1578.

4. Chan S.M., Chan E.K.W., Chu W.C.W., et al. (2011). Hypertrophic pyloric stenosis in a newborn: a diagnostic dilemma. Hong Kong Med J, 17(3), 245-247.

5. Calle-Toro J.S., Kaplan S.L., and Andronikou S. (2020). Are we performing ultrasound measurements of the wall thickness in hypertrophic pyloric stenosis studies the same way?. Pediatr Surg Int, 36(3), 399-405.

6. Demian M., Nguyen S., and Emil S. (2009). Early pyloric stenosis: a case control study. Pediatr Surg Int, 25(12), 1053-1057.

7. Keckler S.J., Ostlie D.J., Holcomb Iii G.W., et al. (2008). The progressive development of pyloric stenosis: a role for repeat ultrasound. Eur J Pediatr Surg, 18(3), 168-170.

\section{NGHIÊN CỨU SƯ THAY ĐỔI NỒNG Độ MộT Số CYTOKINE TRONG HUYẾT TƯƠNG CỦA BỆNH NHÂN BỆNH PHỔI TẮC NGHẼN MẠN TÍNH ĐƯợC ĐIỀU TRI BẰNG GHÉP TẾ BÀO GỐC TRUNG MÔ ĐỒNG LOÀI TỪ MÔ DÂY RốN}

Lê Thị Bích Phượng ${ }^{1}$, Đỗ Quyết ${ }^{2}$, Lê Văn Đông ${ }^{3}$, Cấn Văn Mão ${ }^{4}$, Nguyễn Lĩnh Toàn ${ }^{4}$, Nguyễn Viết Nhung ${ }^{5}$, Đồng Khắc Hưng ${ }^{2}$, Đỗ Minh Trung

\section{TÓM TẮT}

Mục tiêu: Xác định nồng độ và đánh giá sự thay đổi nồng độ một số cytokine trong huyết tương của bệnh nhân (BN) bệnh phổi tắc nghẽn man tính

${ }^{1}$ Bênh viện Đa khoa Vạn Hạnh

2Viên Nghiên cứu Y Dược học Quân sự, Học viện Quân y

${ }^{3}$ Viện Y học Dự phòng Quần đội

${ }^{4}$ Học viên Quần y

${ }^{5}$ Bệnh viên Phổi Trung ương

Chịu trách nhiệm chính: Lê Thị Bích Phượng

Email: drbphuong@gmail.com

Ngày nhận bài: 14.9.2021

Ngày phản biên khoa hoc: 11.11.2021

Ngày duyệt bài: 18.11.2021
(BPTNMT) được ghép bằng tế bào gốc trung mô (TBGTM) đồng loài từ mô dây rốn và huyết tương già̃u tiểu câu. Đối tượng và phương pháp: Các mấu huyết tương của 10 bênh nhân BPTNMT được điều trị bằng phương pháp nội khoa và $18 \mathrm{BN}$ được ghép bằng tế bào gốc trung mô (TBGTM) đồng loài từ mô dây rốn và huyết tương giàu tiểu cầu, được thu nhận tai Bênh viên Phổi Trung ương và Bênh viên đa khoa Vạn Hạnh ớ các thời điểm trước khi ghép tế bào gốc (0) và sau $1,3,7$ và 12 tháng ghép tế bào gốc và được xét nghiệm định lượng nồng độ các cytokine IL$1 \beta$, IL-6, IL-8, IL-10, IFN- $\gamma$, TNF-a và VEGF trong huyết tương bằng phương pháp ELISA. Kết quả: Nồng độ cytokine trước khi điều trị của nhóm chứng cao hơn nhưng không đáng kể so với nhóm điều tri $(p>0,05)$, trừ TNF-a $(p<0,05)$. Sau khi điều trị, ở 